\title{
Laser Powder Bed Fusion of Multilayer Thin-walled Structures Based on Data-driven Model
}

\author{
An-Chen Lee ${ }^{1}$, Ruei-Yu Huang ${ }^{1}$, Trong-Doan Nguyen ${ }^{1}$, Chung-Wei Cheng ${ }^{1}$ and Mi-Ching Tsai ${ }^{2}$ \\ ${ }^{1}$ Department of Mechanical Engineering, National Chiao Tung University, No. 1001, Ta Hsueh Road, Hsinchu 300, Taiwan \\ E-mail: weicheng@nctu.edu.tw \\ ${ }^{2}$ Department of Mechanical Engineering, National Cheng Kung University, Tainan, Taiwan
}

\begin{abstract}
The laser powder bed fusion (LPBF) process has the advantage of directly building metal parts with complex geometries and lattice structures. The lattice structures are usually composed of different thin-walled structures. Therefore, precise control over the shape of structures on the LPBF fabricated lattice structures is important. In this study, a symbolic regression solution that describes the relationship between scan track width and process parameters (laser power and scanning velocity) is generated by empirical data. This regression model is then implemented into the control scheme that stabilizes the structure width for single-layer and multilayer thin-walled structures. The experiment results showed that the average errors for the single-layer track with desired width from $120 \mu \mathrm{m}$ to $180 \mu \mathrm{m}$ are all under $5 \%$, and the average error for the ten-layered structures with desired width $180 \mu \mathrm{m}$ is about $2.2 \%$.
\end{abstract}

DOI: $10.2961 /$ jlmn.2020.01.2007

Keywords: selective laser melting, SLM, symbolic regressed solution, data-driven model

\section{Introduction}

Powder bed fusion (PBF), as described by the ISO/ASTM standard [1], is one technique used in additive manufacturing (AM) for the fabrication of $3 \mathrm{D}$ parts. PBF uses a scanning laser or an electron beam for selectively melting powdered materials, thereby consolidating the powder to form a solid mass. By scanning sliced layers, the powder bed is lowered to deposit a new powdered material, and the process is repeated until the part is $3 \mathrm{D}$ printed. When using a laser in the PBF process, this method is called laser PBF (LPBF) or selective laser melting (SLM) [2-4].

The LPBF process allows for the direct building of metal parts with lattice structures [5]. The advantage of lattice structures is that they are lightweight and can be used in energy [6] and medical [7, 8] applications. The lattice structures are usually composed of thin-walled structures, and a thin wall is built up by a stack of single laser melted tracks in the vertical direction.

The LPBF process selectively heats metallic powders on the powder bed to a melting temperature. The laser power, scanning velocity, and hatch distance determine the energy density transferred to the material; hence, most related studies focus on these parameters $[9,10]$. Different regions in the parameter space, which are scanned by laser power and scanning velocity in LPBF corresponding to fully dense, over-melting, incomplete melting, and overheating parameters are presented in $[11,12]$. The optimal process parameters and scanning strategies are used to fabricate the parts with specific mechanical properties [11, 13-16].

In situ monitoring and quality control the LPBF process with sensors has attracted the attention of researchers seeking to regulate the process [17-21]. However, to realize the real-time closed-loop control in the LPBF process, sensors with a high sampling rate is required. Metal powder absorbs irradiation energy from the laser source, heats up over its melting point, and then liquefies. The melting pool area is about a few hundred microns, and the laser scanning velocity is in the order of magnitude of a few hundred $\mathrm{mm} / \mathrm{s}$, i.e., the high resolution and sampling rate sensors are required for real-time measurement, e.g., for a $120 \mu \mathrm{m}$ melting pool diameter and scanning velocity 1000 $\mathrm{mm} / \mathrm{s}$, the sampling rate of the sensors should be on the order of $10 \mathrm{kHz}$ [19]. In order to solve the above problem, datadriven predictive models have been used to learn the relationships between the inputs and outputs of the LPBF process, enabling parts to be built with the desired properties [22]. However, the data-driven model for on-line control of the LPBF process with stable scan track is less discussed.

In this study, from discretely sampled experiments, the symbolic regression method was utilized to parameterize the model of scan track width versus process parameters (laser power and scanning velocity). This model was then applied in a laser power controller to fabricate the single-layer scan tracks and multilayer thin-walled structures in the vertical direction by sequentially layering melted tracks under the regression model.

\section{Experiments and Data Gathering \\ 2.1 Hardware description}

The experiments were conducted in a laboratory LPBF system, as shown in Fig. 1. The system is composed of a laser and optical module, processing chamber and powder feeding module, working platform module, and system control module. The laser and optical module comprises a fiber laser source (YLR-500-WC-Y14, IPG Photonics) with a central wavelength of $\sim 1070 \mathrm{~nm}$, a maximum average laser power of $500 \mathrm{~W}$, a collimator (focal length $60 \mathrm{~mm}$ ), halfwave plates, polarizing beam splitter, scanner mirrors, and a focusing F-theta lens. The laser beam divergence is 134 mrad at laser output and the diameter was determined to be 
approximately $8.04 \mathrm{~mm}(134 \mathrm{mrad} \times 60 \mathrm{~mm})$. The laser beam with random polarization is polarized by a half-wave plate, essentially resulting in a linear polarized beam. The laser power of the laser beam is adjusted by a secondary rotatable half-wave plate and a polarizing beam splitter. The laser beam transmitted through the F-theta lens (focal length $310 \mathrm{~mm}$ ) is incidental in the normal direction on the metal powder surface. The focal spot diameter was determined to be approximately $76 \mu \mathrm{m}$. A galvanometer scanner with a maximum scanning velocity of $1 \mathrm{~m} / \mathrm{s}$ and a scanning field of $100 \times 100 \mathrm{~mm}^{2}$ is used to position the focused laser beam.

The LPBF process takes place inside the chamber with a protective nitrogen gas atmosphere. The LPBF part is built on the base plate, which is mounted onto the platform carrier with a pre-heating module. The pre-heating module reduced the temperature gradients, thereby ensuring good bonding of the first layers. The elevator system moves the platform base in a vertical direction based on the slice thickness. The powder feeding module is comprised of the powder dispenser and recoater module. The recoater uses scrapers to deposit the powders on the base plate, and layer thickness can be adjusted by the thick gauge. For iron-based materials, a higher oxygen content (e.g. 3\%) results in more spherical droplets [23]. The morphology of melted track is affected by the oxygen concentration. In the following experiments, the oxygen concentration and pre-heating temperature were controlled at $1.97 \%$ and $200^{\circ} \mathrm{C}$, respectively.

The system control module for the LPBF building process is realized by a Windows-kernel industrial PC with CoDeSys software. The controlling program can govern the galvanometer scanner and laser power control module (a rotatable half-wave plate) by communicating with the system through the EtherCAT protocol. Different modules for specific track width can be built into the controller program. By selecting the desired track width, the controller program synchronously controls the half-wave plate (different laser power) as well as the galvanometer scanner according to the module during the LPBF process, which can realize the function of controlling the track width even in high-curvature or corner regions.

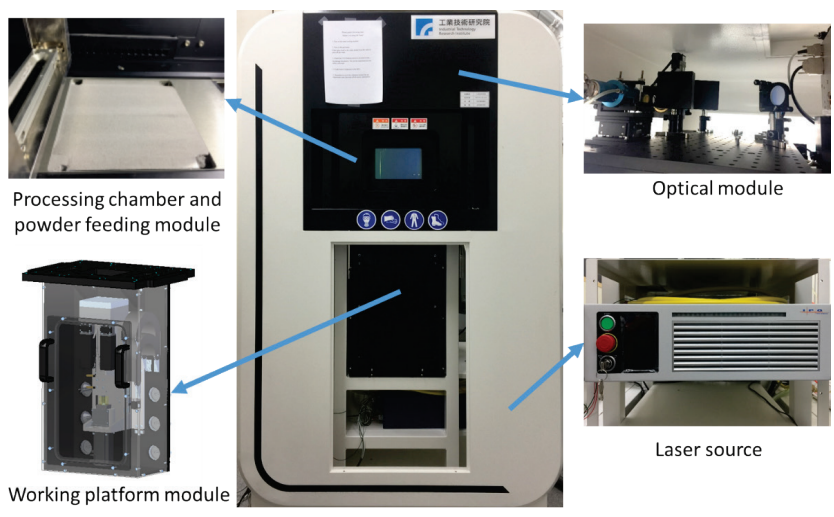

Fig. 1 The laboratory LPBF system.

\subsection{Data gathering}

The single laser melted tracks are the essential 3D structure units, and the melted track characteristics of the first layer on the substrate were investigated. The maraging steel powders (EOS MS1, particle size distribution $\sim 30 \mu \mathrm{m}$ ) with a layer thickness between $30 \mu \mathrm{m}$ and $40 \mu \mathrm{m}$ were deposited on a base plate (S45C) substrate by the recoater. Different combinations of process parameters [24], i.e., laser power and scanning velocity result in different kinds of melted tracks: continuous, balled, and not fully melted. This study conducted a factorial experiment and scanned a series of single straight-line tracks by laser power $(P)$ varying in a range from $10 \mathrm{~W}$ to $100 \mathrm{~W}$ with $5 \mathrm{~W}$ step as the scanning velocity (v) was gradually increased from $10 \mathrm{~mm} / \mathrm{s}$ to 100 $\mathrm{mm} / \mathrm{s}$.

Fig. 3 presents the surface morphology of the single straight-line tracks on the substrate at the value of laser power $P=55 \mathrm{~W}$. At the scanning velocity of $10-20 \mathrm{~mm} / \mathrm{s}$, it was observed that both sides of the melted track were nonuniform (marked by yellow dashes). When the scanning velocity was slow, the irradiated time on the powder surface was prolonged, the heat affected zone was increased, and the subsequent solidification structure had large round morphology. The structure became continuous when the scanning velocity increased. As the scanning velocity increased to a certain level, i.e., $100 \mathrm{~mm} / \mathrm{s}$, the single track turned from a continuous form into a discontinuous type. This can be explained by Rayleigh-Plateau instability: the radial and transverse directions of the melt track shrink excessively during solidification, and a drop-shaped broken line track is formed $[25,26]$.

The 130 experiments for $P \geq 40 \mathrm{~W}$, as the power density was high enough to create continuous melted tracks. Fig. 2 shows the dependence of the scan track width on the process parameters laser power $P$ and scanning velocity $v$. It is clear that the overall tendency is that as the laser power decreased or scanning velocity increased, the scan track width decreased.

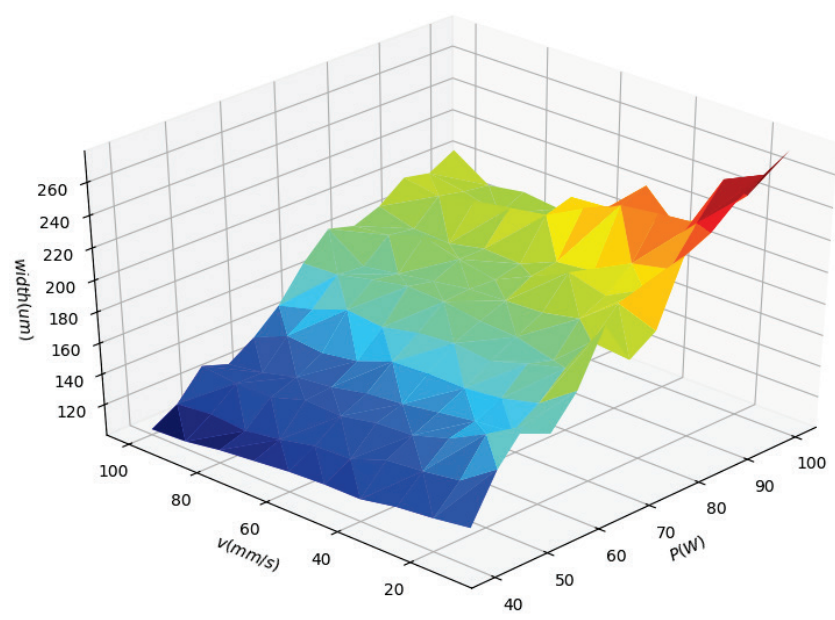

Fig. $23 \mathrm{D}$ plot of scan track width vs. laser power $P$ and scanning velocity $v$. 


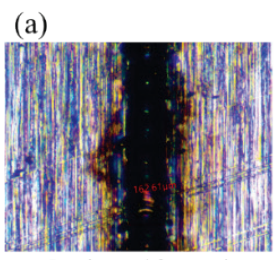

velocity: $10 \mathrm{~mm} / \mathrm{s}$ width: $162.61 \mu \mathrm{m}$

(f)

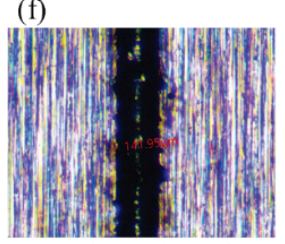

velocity: $60 \mathrm{~mm} / \mathrm{s}$ width: $141.95 \mu \mathrm{m}$ (b)

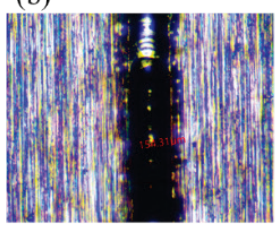

velocity: $20 \mathrm{~mm} / \mathrm{s}$ width: $154.31 \mu \mathrm{m}$

(g)

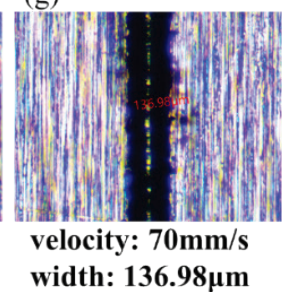

(c)

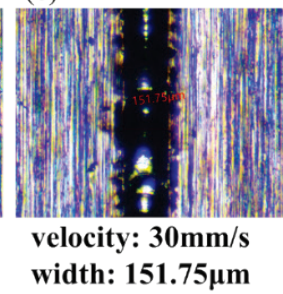

(h)

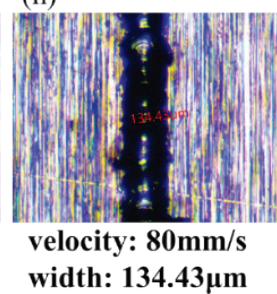

(d)

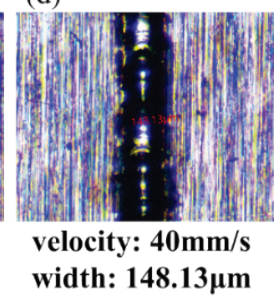

(i)

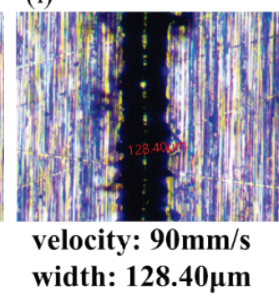

(e)

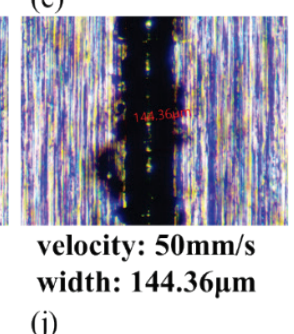

(j)

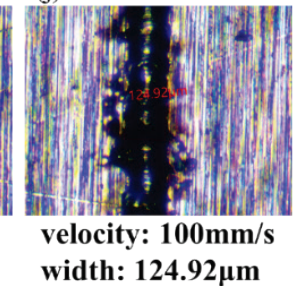

Fig. 3 Microscope images of the single straight-line tracks fabricated by power $55 \mathrm{~W}$ and different scanning velocities.

\section{Symbolic Regression Models}

In this study, the hierarchical model of laser power control was organized: a high-level governing system plans suitable value of $P$ was based on current scanning velocity $v$ and desired scan track width; a lower-level controller was then in charge of rotating the half-wave plate, with suitable angle corresponding to that value of $P$ on the powder layer. The ultimate goal was to maintain the consistency of the scan track width during the LPBF process as stable as possible via utilizing laser power. Thus, it was crucial to know the relationships among the scan track width, laser power and scanning velocity. As these relationships were unveiled from the experimental data, the appropriate processing parameters needed to achieve the desired highlevel process control LPBF can be obtained.

In traditional regression methods, one needs to predefine the model structure before the regression starts. The selection of model form highly affects the fitness and therefore is a crucial step in the regression method. The selection of model structure is usually based on the physical models or prior knowledge of the users that is, the form of model might be biased and limited by the professional knowledge. For some extremely complicated processes such as LPBF, it is hard to choose a simple model structure for regression.

For generating the model of the LPBF process, one can use regression methods like symbolic regression, or AI (Artificial Intelligence)-based methods like convolution neural network. For the symbolic regression method, the model structure does not need to be pre-specified. The symbolic regression method is based on genetic programming, which can make the model iteratively evolve from generation to generation. Both the coefficient and arithmetic operation can be changed during the regression process. By selecting the basis-functions and then training the model, one not only can distill some factors with physical meanings from experimental data but also find a useable model for further control application by the symbolic regression method [27]. Therefore, the symbolic regression method is adopted for generating the process model for the present study.
This study used Eureqa [27], an AI powered modeling engine for symbolic regression. For the purpose of our study, the model between scan track width and input process parameters (laser power and scanning velocity) needs to be found. The theoretical models that predict a linear rise of the melt pool area with laser power and an exponentially decaying influence of the scanning velocity are given in [17] In this study, considering that the exponential term might be an important basis-function for the LPBF model, the basisfunctions of constant, addition, subtraction, multiplication, division, power, exponential, and input variables are selected for symbolic regression in Eureqa.

Eureqa can automatically select the appropriate size of training and validation data sets depending on the total size of the data base. This study used a default splitting setting, which lets Eureqa decide the splitting percentage of the research data set. Using 130 collected experimental data (see Table 1), it turned out that 116 of them were used for training and 14 for validation; a model for scan track width based on laser power and scanning velocity can thus be identified. The regression result of the model with a best fit standard in the series of complex solutions given by Eureqa is shown in Fig. 4. Each incline from the left to right curve segment of the red line plot corresponds with one particular value of laser power $P$ and scanning velocity $v$, which is increased from left to right for each segment.

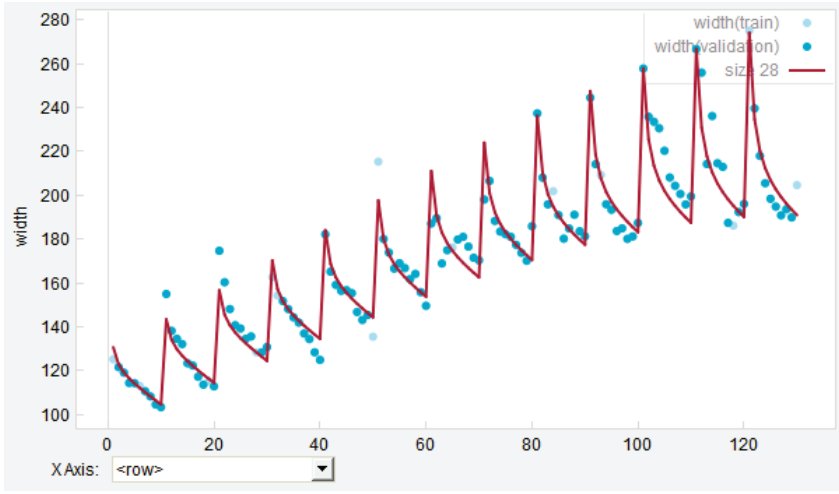

Fig. 4 Plot of the selected solution model. 
Table 1 Detailed track width of the built sample tracks.

\begin{tabular}{|c|c|c|c|c|c|}
\hline $\begin{array}{c}\text { Desired } \\
\text { width }(\mu \mathrm{m})\end{array}$ & $\begin{array}{c}\text { Velocity } \\
(\mathrm{mm} / \mathrm{s})\end{array}$ & $\begin{array}{c}\text { Actual } \\
\text { width }(\mu \mathrm{m})\end{array}$ & $\begin{array}{c}\text { Desired } \\
\text { width }(\mu \mathrm{m})\end{array}$ & $\begin{array}{c}\text { Velocity } \\
(\mathrm{mm} / \mathrm{s})\end{array}$ & $\begin{array}{c}\text { Actual } \\
\text { width }(\mu \mathrm{m})\end{array}$ \\
\hline \multirow{11}{*}{180} & 10 & 176.02 & \multirow{11}{*}{160} & 10 & 160.44 \\
\hline & 20 & 166.22 & & 20 & 162.66 \\
\hline & 30 & 178.30 & & 30 & 165.63 \\
\hline & 40 & 183.27 & & 40 & 162.28 \\
\hline & 50 & 184.69 & & 50 & 158.38 \\
\hline & 60 & 166.75 & & 60 & 162.37 \\
\hline & 70 & 165.02 & & 70 & 161.65 \\
\hline & 80 & 164.66 & & 80 & 160.38 \\
\hline & \begin{tabular}{|l|} 
Average \\
\end{tabular} & 173.12 & & \begin{tabular}{|l|} 
Average \\
\end{tabular} & 161.72 \\
\hline & Error $(\mu \mathrm{m})$ & 6.88 & & Error $(\mu \mathrm{m})$ & 1.72 \\
\hline & Error (\%) & 3.82 & & Error (\%) & 1.08 \\
\hline $\begin{array}{c}\text { Desired } \\
\text { width }(\mu \mathrm{m})\end{array}$ & $\begin{array}{c}\text { Velocity } \\
(\mathrm{mm} / \mathrm{s})\end{array}$ & $\begin{array}{c}\text { Actual } \\
\text { width }(\mu \mathrm{m})\end{array}$ & $\begin{array}{c}\text { Desired } \\
\text { width }(\mu \mathrm{m})\end{array}$ & $\begin{array}{l}\text { Velocity } \\
(\mathrm{mm} / \mathrm{s})\end{array}$ & $\begin{array}{c}\text { Actual } \\
\text { width }(\mu \mathrm{m})\end{array}$ \\
\hline \multirow{11}{*}{140} & 10 & 124.77 & \multirow{11}{*}{120} & 10 & 109.64 \\
\hline & 20 & 143.59 & & 20 & 114.37 \\
\hline & 30 & 144.31 & & 30 & 121.88 \\
\hline & 40 & 127.15 & & 40 & 112.35 \\
\hline & 50 & 139.32 & & 50 & 114.82 \\
\hline & 60 & 131.86 & & 60 & 121.78 \\
\hline & 70 & 124.56 & & 70 & 112.38 \\
\hline & 80 & 134.49 & & 80 & 118.35 \\
\hline & Average & 133.76 & & Average & 115.70 \\
\hline & Error $(\mu \mathrm{m})$ & 6.34 & & Error $(\mu \mathrm{m})$ & 4.30 \\
\hline & Error (\%) & 4.46 & & Error (\%) & 3.59 \\
\hline
\end{tabular}

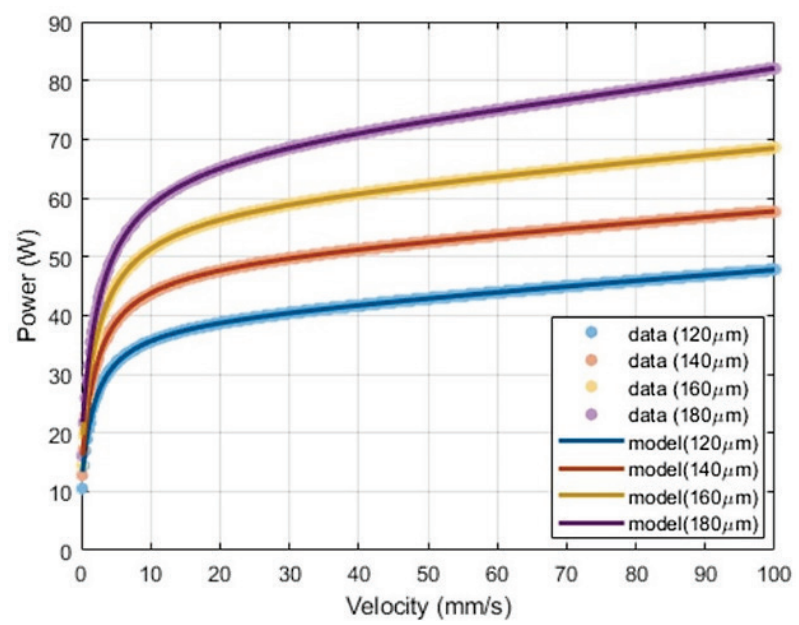

Fig. 5 Model of laser power versus scanning velocity for different widths.

Based on the experimental data shown in Table 1 and after evaluating 151,161 times of generations and billions of equations, the Eureqa software will place all the models on a Pareto chart based on their rank of complexity and accuracy. The users can choose a suitable model that satisfies their needs. To prevent the overfitting problem of the regression model, this research selected Equation (1), which presents the scan track width. The obtained model has $\mathrm{R}^{2}=0.949$, RMSE (root-mean-square error) $=8.187$, and correlation coefficient $=0.975$.

Width $(\mu \mathrm{m})=a+b \cdot P^{2}+\frac{c \cdot P^{2}}{v}+d \cdot v+e \cdot P^{3}$

$a=74.0324583264964 ; b=0.0397045894925754 ; c=0.0756018352030015$;

$d=-0.1680420888199 ; e=-0.000270877747700316$

where $P$ is laser power, $v$ is scanning velocity, and $a$ to $e$ are the coefficients. R-squared $\left(\mathrm{R}^{2}\right)$, a statistical measure that represents the proportion of the variance for a dependent variable that is explained by an independent variable or variables in a regression model, is often used to determine the fitness of a regression model. Because the $\mathrm{R}^{2}$ value is very high in this case, it is believed that this model is accurate enough to describe the LPBF process. Furthermore, the independent variable and interaction terms between them in this model also passed the F-test and p-test in ANOVA at an alpha level of 0.05. Note that the Eureqa software was able to find various possible models (equations), and the fitness in the solution results sheet is an error measure of how well it fits the data [27].

A previous study used a first-order transfer function to describe the relationship between the melt pool area and the laser power [17]. However, the solidification process was not considered. The nonlinear polynomial function model of Eq. (1) is suitable for representing the relationships of solidified scan track width and process parameters. By observing the relationship among all five terms of the right hand side, one can see that the first term $a$ is an offset, and the second term with coefficient $b$ is the main affection to the process. When the laser power is higher, the width will be enlarged by the square value of the laser power. For the third and fourth terms, the coefficients and equation forms then show that when the scanning velocity increase, the track width will decrease. The last term of the right hand side with a negative coefficient $e$ shows that even the second terms make the track width a positive correlation with the square value of the laser power, and the positive correlation will decrease when the laser power is very large.

To control the laser power for the LPBF process with a given specific track width, the model for different track widths needs further simplified. The value of scan track width was kept constant for four cases: Width $=180 \mu \mathrm{m}, 160$ $\mu \mathrm{m}, 140 \mu \mathrm{m}$, and $120 \mu \mathrm{m}$, respectively. Laser power $P$ in Eq. (1) was then solved with $v$ varying from $0.01 \mathrm{~mm} / \mathrm{s}$ to 100 $\mathrm{mm} / \mathrm{s}$. Next, that data were feed into Eureqa again, and the contour-line Width $=120 \mu \mathrm{m}, 140 \mu \mathrm{m}, 160 \mu \mathrm{m}$, and $180 \mu \mathrm{m}$ of Eq. (1) was re-modeled to obtain Eqs. (2), (3) (4) and (5), respectively. Fig. 5 shows the model of laser power versus scanning velocity for width $=120 \mu \mathrm{m}, 140 \mu \mathrm{m}, 160 \mu \mathrm{m}$, and $180 \mu \mathrm{m}$. The reconstructed symbolic regression model is nearly perfect, because the model (lines) is close to the training data (dots). These equations were then directly inserted into the program that controls the laser power (i.e., different angle of half-wave plate) which governs the irradiation power density on the powder bed.

The formula of laser power $P$ depending on velocity when Width $=120 \mu \mathrm{m}$ is:

$P_{120}(\mathrm{~W})=a+b \cdot v+c \cdot v^{2}+\frac{d}{e+f . v}$

$a=39.3734554998629 ; b=0.0931736453106274 ; c=-4.01644759609477 e-5$;

$d=-12.2862763359667 ; e=0.42787205876283 ; f=0.218626376490188$

The model at Width $=140 \mu \mathrm{m}$ is given as:

$P_{140}(\mathrm{~W})=a+b \cdot v+c \cdot v^{2}+\frac{d}{e+f . v}$

$a=49.2013718856553 ; b=0.0978215998130318 ; c=-4.9596421968858 \mathrm{e}-5$;

$d=-16.9181033669951 ; e=0.466804354193228 ; f=0.217170277499672$

The laser power $\mathrm{P}$ equation at Width $=160 \mu \mathrm{m}$ is given as:

$P_{160}(\mathrm{~W})=a+b \cdot v+c \cdot v^{2}+\frac{d}{e+f \cdot v}+g \cdot v^{3}$

$a=58.9095563858813 ; b=0.111252919505445 ; c=-7.33212607871529 e-5$;

$d=-24.4296921819018 ; e=0.577729967976006 ; f=0.222212343570381$;

$g=2.36146667086618 e-7$ 
The forth model at Width $=180 \mu \mathrm{m}$ is given as:

$P_{180}(\mathrm{~W})=a+b \cdot v+c \cdot v^{2}+\frac{d}{e+f \cdot v}+g \cdot v^{3}$

$a=67.1037677063407 ; b=0.205611933765688 ; c=-0.0010074685830731 ;$

$d=-133.136410644006 ; e=2.73650384393977 ; f=1.0 ;$

$g=5.79151012701671 e-6$

Equations (2)-(5) describe the nonlinear relationship between laser power $P$ and scanning velocity $v$ toward achieving the goal of maintaining the scan track width as uniform as possible. Interesting, the coefficient $c$ of $v^{2}$ in all four equations is very small. Moreover, the linear parameter $b \cdot v$ aligns with $d /(e+f \cdot v)$ that is destructive to each other in reducing the incline angle of the plots (Fig. 5). As shown, the laser power is sharply decreased to zero as the scanning process stops. Ideally, the laser power should be zero as scanning velocity $v=0$. The incline angle of the curve becomes smaller as the scanning velocity increases. Equations (4) and (5) present $v^{3}$ with the negligible coefficient $g$. In general, this term $g \cdot v^{3}$ only makes a micro improvement in reducing the fit standard of the model in Eureqa. However, it increases the order of complexity in the observed Eqs. (4) and (5).

\section{Experimental Verification of the Hypothesis Models 4.1 Scan tracks of the first layer}

Since the single scan tracks were the essential structure unit of the multilayer structures, the melted track of the first layer on the substrate was first investigated. The pattern of eight segmental tracks with different scanning velocity as shown in Fig. 6(a) was scanned with each model described in the preceding section. For each desired track width, three times of experiments were performed. Fig. 6(b)-(e) illustrate the representative images of scan tracks of the first layer for desired widths $120 \mu \mathrm{m}, 140 \mu \mathrm{m}, 160 \mu \mathrm{m}$, and $180 \mu \mathrm{m}$, respectively. In Fig. 6(a), the reference scanning path and scanning velocity were assigned in G-code that increases from $10 \mathrm{~mm} / \mathrm{s}$ (track 1) to $80 \mathrm{~mm} / \mathrm{s}$ (track 8) during eight tracks of the whole scan path. Laser power was appropriately utilized to keep the scan track width as constant as possible, e.g. Eqs. (2)-(5) for the different scan track widths. These equations were directly inserted into the program that controls the laser power.

Fig. 7(a) shows a schematic measurement position of the scanning pattern, and Fig. 7(b) and Fig. 7(c) show an example of the microscopic images at the middle point and transition point of scanned paths when Width $=180 \mu \mathrm{m}$, respectively. As the velocity was gradually increased during each path, the laser power value was assigned appropriately so that the actual track width was as close as possible to the desired one, e.g., Eq. (5) for the Width $=180 \mu \mathrm{m}$ case.

From the results shown in Fig. 7(c), it was found at the transition point between lines that there is a slight difference in track width. The dark area at the tipping point between two tracks indicates the occurrence of the discontinuous melted track, which is due to the low scanning velocity. When the scanning velocity is too slow, the irradiated time on the powder surface is prolonged, more powder materials were evaporated from the melt pool, and the solidification structure has discontinuous morphology. (a)

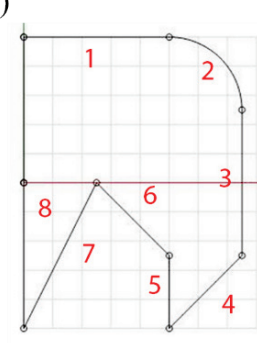

(b)

(c)

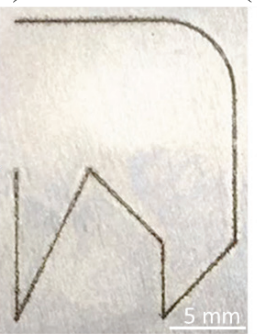

(d)

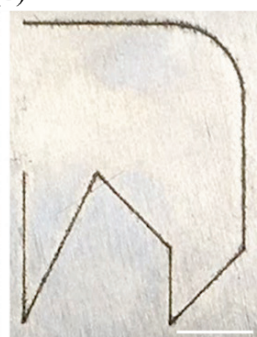

(e)

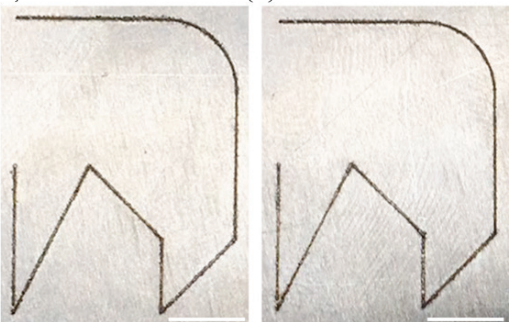

Fig. 6 (a) schematic scanning pattern and images of scan tracks of the first layer for desired widths: (b) $120 \mu \mathrm{m}$, (c) $140 \mu \mathrm{m}$, (d) $160 \mu \mathrm{m}$, and (e) $180 \mu \mathrm{m}$.

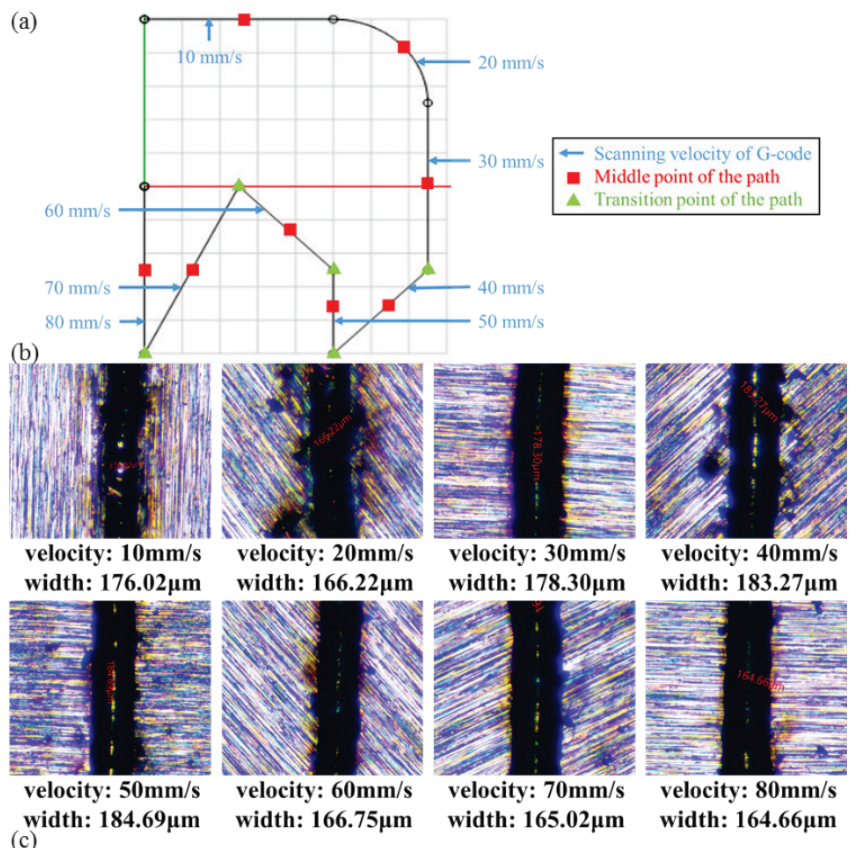
(c)

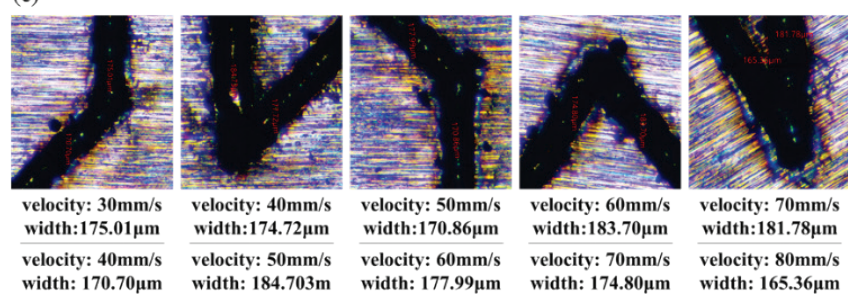

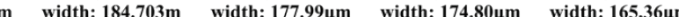
Fig. 7 (a) schematic measurement position of the scanning pattern and microscope images of scan track width when width $=180 \mu \mathrm{m},(\mathrm{b})$ and for the middle, and (c) transition points of the paths.

During the transition period between two consecutive lines, the system was adapted to overcome the high accumulated energy as the scanning velocity decreased. In 
CNC control, at every single track, the scan includes three steps: accelerating, constant speed and decelerating. Thus, the noteworthy period is at the transition between two tracks. The fact that scanning velocity decreased to zero then increased around the corner could lead to the heat accumulation effect that causes overheating if the laser power is not well adjusted.

In fact, owing to the hardware characteristics, in controlling laser power by the half-wave plate, there is a limited acceleration of the motor to control the angle of this plate. As shown in Fig. 5, at the low value of scanning velocity, the laser power changed dramatically. Although the trial experiments did not cover those extreme low speeds, the above situation could occur, especially at the tipping point between two tracks. However, this quick change in velocity led to the exceeding of the acceleration capacity of the half-wave plate controlling motor. Thus, in implementing the validating hypothesis models, the power in the power calculating function was clamped to $v=10$ $\mathrm{mm} / \mathrm{s}$ when $v \leq 10 \mathrm{~mm} / \mathrm{s}$. It is likely to accumulate energy at the tipping points. Fortunately, the transition time is very short due to the high acceleration of the scanning movement by the galvanometer scanner. Therefore, it caused a negligible consequence to the scanning process. As shown in Fig. 7(c) at the transition point between lines, there is a slight difference in track width.

\subsection{Multilayer thin-walled structures}

Fig. 8(a) presents the images of the ten-layered structures fabricated with the pattern (Fig. 6(a)) and the desired width $180 \mu \mathrm{m}$. The first layer was melted with the same parameters described in section 4.1, and the second layer to the tenth layer were melted by the model of Eq. (5) with a power correction coefficient of 0.9 .

The power correction coefficient is added from both theoretical and experimental reasoning. As for the scanning tracks at the second layer and above, because both the base solid area and thermal conductivity are much smaller than the first layer [28], a power correction coefficient should be added to reduce the laser power at the second and subsequent layers; otherwise, the scanning width might be larger than the one at the first layer. By doing several small experiments, the power correction coefficient 0.9 was an appropriate value to form a multi-layer structure with high consistence of scan width.

Fig. 8(b) presents an example of the top-view microscopic images at the middle point of the scanned paths. The average top structure width of the third to eighth segmental tracks is about $183.9 \mu \mathrm{m}$, and the error is about 2.2\%. In Fig. 8(b), it can be seen that the structure's width for $\mathrm{v}=10 \mathrm{~mm} / \mathrm{s}$ is $230.04 \mu \mathrm{m}$, with a non-uniform pattern. When the scanning velocity was slow, e.g., $10 \mathrm{~mm} / \mathrm{s}$ in this study, the irradiated time and the heat affected zone were increased, and the subsequent solidification structure had large round morphology.

Fig. 8(c) presents the side view microscopic images of the path with $30 \mathrm{~mm} / \mathrm{s}$ scanning velocity. The height of the vertical structure above the substrate surface is about 626 $\mu \mathrm{m}$, which is higher than the total amount of the ten powder layer thickness $490 \mu \mathrm{m}$. During the fabrication of the multilayer thin-walled structures, the melted track on both sides was surrounded by powder materials, the main heat conduction went to the previous solidified layers, and the track height is usually slightly higher than the powder layer thickness [29].
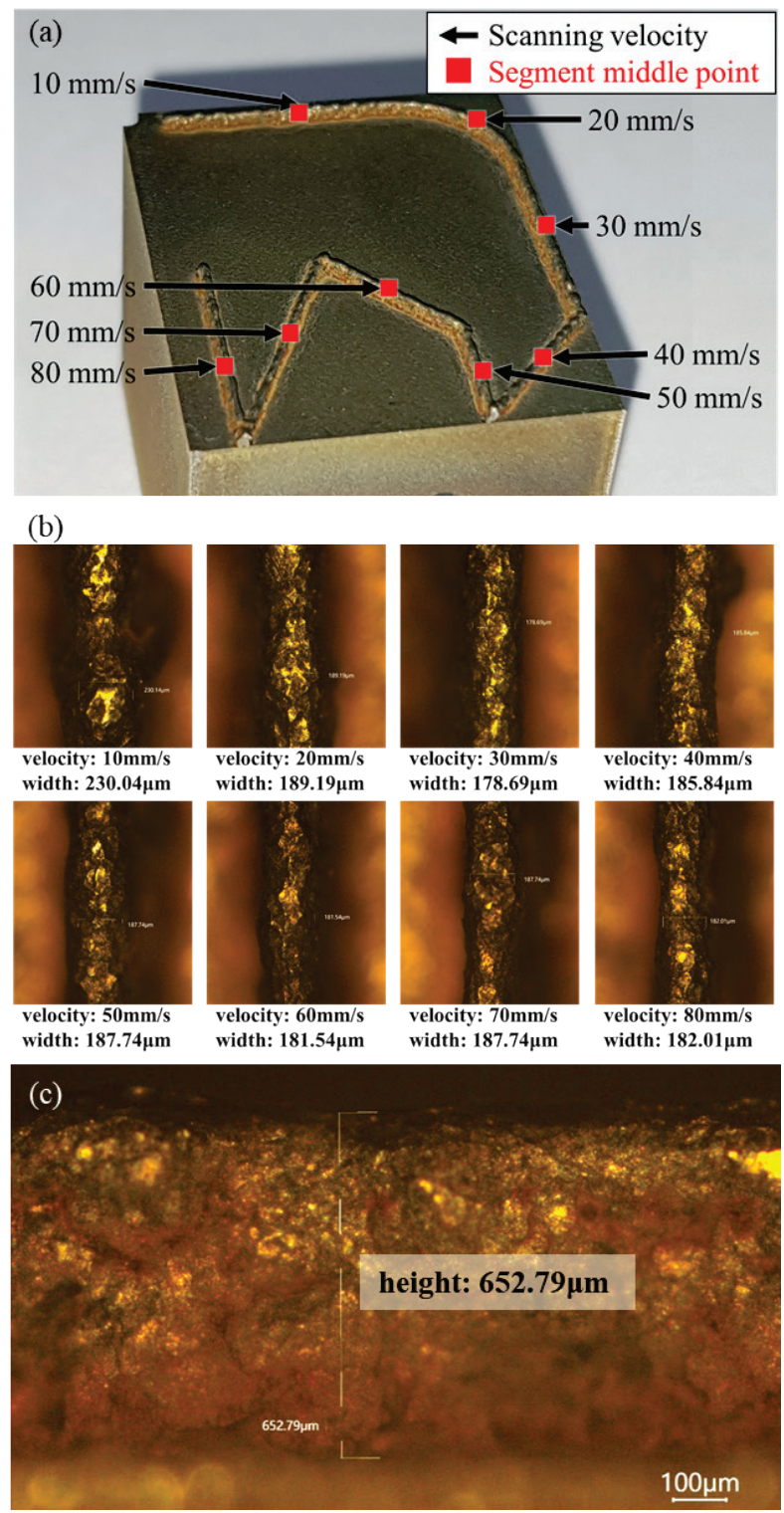

Fig. 8 (a) measurement position of the ten-layered structures with desired width $180 \mu \mathrm{m}$ (b) the middle point of the paths, and (c) the side view of the path with $30 \mathrm{~mm} / \mathrm{s}$ scanning velocity.

\section{Conclusion}

This study used a laser power controller to control the scanning track width of the SLM process based on empirical data. The relationship between process signatures (scan track width) and process parameters (laser power $P$, scanning velocity $v$ ) was utilized to improve the geometric properties. Symbolic regression models were applied to control laser power that retains the scan track width at a stable value. Different values of scan track widths validated the versatility of the hypothesis. The results proved the accuracy of the proposed model, with average relative errors 
for different track width under 5\%. In this study, the experiments were only conducted on thin-walled structures. To truly perform the data-driven model in building complex parts, adding more features, such as remelted depth and track height into the model may improve the model's performance.

\section{Acknowledgements}

This work was supported by the Ministry of Science and Technology of Republic of China, under Contracts MOST 105-2221-E-009 -064 -MY3 and MOST 107-2218E-006-019.

\section{References}

[1] I. ASTM: Standard Terminology for Additive Manufacturing-General Principles-Terminology, ASTM Int., West Conshohocken (2015).

[2] F. Abe, K. Osakada, M. Shiomi, K. Uematsu, and M. Matsumoto: J. Mater. Process. Tech., 111, (2001) 210.

[3] M. Schmidt, M. Merklein, D. Bourell, D. Dimitrov, T. Hausotte, K. Wegener, L. Overmeyer, F. Vollertsen, and G. N. Levy: CIRP Annals, 66, (2017) 561.

[4] H. Lee, C.H. J. Lim, M.J. Low, N. Tham, V.M. Murukeshan, and Y.J. Kim: J. Pr. Eng. Man.-G.T., 4, (2017) 307.

[5] C. Yap, C. Chua, Z. Dong, Z. Liu, D. Zhang, L. Loh, and S. Sing: Appl. Phys. Rev., 2, (2015) 041101.

[6] M. Ameli, B. Agnew, P.S. Leung, B.Ng, C.J. Sutcliffe, J. Singh, and R. McGlen: Appl. Therm. Eng., 52, (2013) 498.

[7] T. Habijan, C. Haberland, H. Meier, J. Frenzel, J. Wittsiepe, C. Wuwer, C. Greulich, T.A. Schildhauer, and M. Köller: Mat. Sci. Eng. C, 33, (2013) 419.

[8] B. Gorny, T. Niendorf, J. Lackmann, M. Thoene, T. Troester, and H.J. Maier: Mat. Sci. Eng.: A, 528, (2011) 7962.

[9] H. Gu, H. Gong, D. Pal, K. Rafi, T. Starr, and B. Stucker: Proc. 24th Int. Symp. Solid Freeform Fabrication, Austin, (2013) p.474.

[10] T. P. M. Islama, H. Piilia, A. Salminena, and O. Nyrhilä: Phys. Procedia, 41, (2013) 835.

[11] H. Gong: University of Louisville Ph.D. Dissertation, (2013).

[12] T. Childs, C. Hauser, and M. Badrossamay: CIRP Ann.Manuf. Techn., 53, (2004) 191.

[13] J.P. Kruth, L. Froyen, J. Van Vaerenbergh, P. Mercelis, M. Rombouts, and B. Lauwers: J. Mater. Process. Tech., 149, (2004) 616.

[14] L. Thijs, F. Verhaeghe, T. Craeghs, J.V. Humbeeck, and J.P. Kruth: Acta Mater, 58, (2010) 3303.

[15] E. Yasa, J. Deckers, and J.P. Kruth: Rapid Prototyping J., 17, (2011) 312.

[16] J.P. Kruth, J. Deckers, E. Yasa, and R. Wauthle: Proc. Ins. Mech Eng. B-J. Eng. Manuf., 226, (2012) 980.

[17] T. Craeghs, F. Bechmann, S. Berumen, and J.P. Kruth: Phys. Procedia, 5, Part B, (2010) 505.

[18] J. Mireles, C. Terrazas, S.M. Gaytan, D.A. Roberson, and R.B. Wicker: Int. J. Adv. Manuf. Technol., 78, (2015) 1193.
[19] S. Clijsters, T. Craeghs, S. Buls, K. Kempen, and J.P. Kruth: Int. J. Adv. Manuf. Technol., 75, (2014) 1089.

[20] V. Renken, S. Albinger, G. Goch, A. Neef, and C. Emmelmann: CIRP-JMST, 19, (2017) 57.

[21] M. Doubenskaia, M. Pavlov, S. Grigoriev, E. Tikhonova, and I. Smurov: J Laser Micro Nanoen, 7, (2012) 236 .

[22] C. Kamath: Int. J. Adv. Manuf. Technol., 86, (2016) 1659.

[23] M. Rombouts, J.P. Kruth, L. Froyen, and P. Mercelis: CIRP Annals, 55, (2006) 187.

[24] T.H.C. Childs, C. Hauser, and M. Badrossamay: CIRP Ann.-Manuf. Techn., 53, (2004) 191.

[25] A.V. Gusarov, I. Yadroitsev, P. Bertrand, and I. Smurov: Appl. Surf. Sci., 254, (2007) 975.

[26] D. Gu and Y. Shen: J. Alloy. Compd., 432, (2007) 163.

[27] M. Schmidt and H. Lipson: Science, 324, (2009) 81.

[28] C.W. Cheng, Y.W. Liou, A.C. Lee, and M.C. Tsai: J Laser Micro Nanoen, 14, (2019) 138.

[29] T. Craeghs, S. Clijsters, E. Yasa, F. Bechmann, S. Berumen, and J.P. Kruth: Opt. Laser Eng, 49, (2011) 1440 .

(Received: November 11, 2019, Accepted: March 17, 2020) 